\title{
PENERAPAN ALGORITMA GREEDY UNTUK PREDIKSI EFEKTIFITAS PENGGUNAAN DAYA LISTRIK
}

\author{
${ }^{1}$ Febrian Dwi Putra, ${ }^{2}$ Zulfikar, ${ }^{3}$ Agus Sifaunajah \\ 1,2,3 Universitas KH. Wahab Hasbullah, Indonesia \\ Ifebritecno0@gmail.com; 2zulfikardia@gmail.com; ;agus.syifa@unwaha.ac.id;
}

\begin{tabular}{l}
\hline \hline Article Info \\
\hline Article history: \\
Received, 26/11/2020 \\
Revised, 30/11/2020 \\
Accepted, 1/12/2020 \\
\\
Kata Kunci: \\
Algoritma Greedy \\
NodeMcu \\
Message Queueing Telemetry \\
Transport (MQTT) \\
Intensitas Konsumsi Energi (IKE) \\
\end{tabular}

\begin{abstract}
ABSTRAK
Banyaknya konsumsi listrik tanpa memperhatikan pola penggunaan mengakibatkan terjadinya penggunaan listrik tidak efektif. Saat ini untuk mengetahui besaran energi listrik yang digunakan hanya dapat dilihat pada Kwh meter, sehingga untuk mengetahui banyaknya penggunaan listrik pada ruangan belum memungkinkan. Sistem monitoring penggunaan listrik pada ruangan menggunakan NodeMcu, MQTT (Message Queueing Telemetry Transport) dan Firebase Database menjadi solusi dari permasalahan diatas.Mikrokontroller NodeMcu sebagai pembaca nilai daya listrik. Dari penelitian ini dilakukan pengujian terhadap pola penggunaan listrik dengan bantuan algortima greedy pada aplikasi android yang dirancang sebagai media penyedia informasi penggunaan daya listrik. Menggunakan standar nilai IKE (Intensitas Konsumsi Energi) sebagai batasan dalam proses algoritma greedy untuk prediksi pola penggunaan listrik telah efektif atau tidak. Hasil dari pengujian menunjukan bahwa penerapan algoritma greedy dapat membantu mengatur pola penggunaan daya listrik menjadi lebih efektif dengan nilai IKE sebesar 3,3 dan tidak melebihi batas target $<3,4$ dibandingkan dengan penggunaan normal sebesar 4.8 .
\end{abstract}

\section{ABSTRACT}

Keywords:

Algoritma Greedy

NodeMcu

$M Q T T$

Energy Consumption Intensity

\begin{abstract}
A large amount of electricity consumption without paying attention to usage patterns results in ineffective use of electricity. Currently, to find out the amount of electrical energy used can only be seen in the Kwh meter, so it is not possible to know the amount of electricity used in the room. The monitoring system of electricity usage in the room using NodeMcu, MQTT (Message Queuing Telemetry Transport), and Firebase Database is a solution to the above problems. The NodeMcu microcontroller as a reader of electrical power values. From this research, testing of electricity usage patterns with the help of greedy algorithms on an android application is designed as a medium for providing information on electricity usage. Using the standard IKE (Energy Consumption Intensity) value as a limitation in the greedy algorithm process for predicting electricity usage patterns is effective or not. The results of the test show that the application of the greedy algorithm can help regulate the pattern of electric power usage to be more effective with an IKE value of 3.3 and not exceeding the target limit $<3.4$ compared to the normal use of 4.8 .
\end{abstract}

This is an open access article under the CC BY-SAlicense.

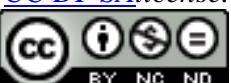

\author{
Penulis Korespondensi: \\ Febrian Dwi Putra, \\ Program Studi Informatika, \\ Universitas KH. Wahab Hasbullah Indonesia, \\ Email:febritecno0@gmail.com
}

\section{PENDAHULUAN}

Algoritma Greedy merupakan sebuah metode untuk menyelesaikan masalah secara bertahap, dimana tiap langkah akan diambil pilihan terbaik guna mendapatkan hasil akhir dengan efektifitas paling tinggi [1] [2] [3] [4]. Energi listrik pada saat ini menjadi sebuah kebutuhan pokok untuk setiap manusia setelah kebutuhan makan dan minum [4][5][6]. Mulai dari peralatan elektronik yang jarang kita gunakan sampai peralatan elektronik yang sering digunakan dan kita jumpai tiap harinya. Namun, penggunaan peralatan elektronik diluar 
kendali oleh penggunanya. Mengakibatkan lonjakan pada konsumsi daya listrik. Untuk menciptakan sebuah efektifitas pada konsumsi daya listrik diperluhkan sebuah pola penggunaan terhadap pada peralatan elektronik yang sering dipakai tiap harinya.[7][8]
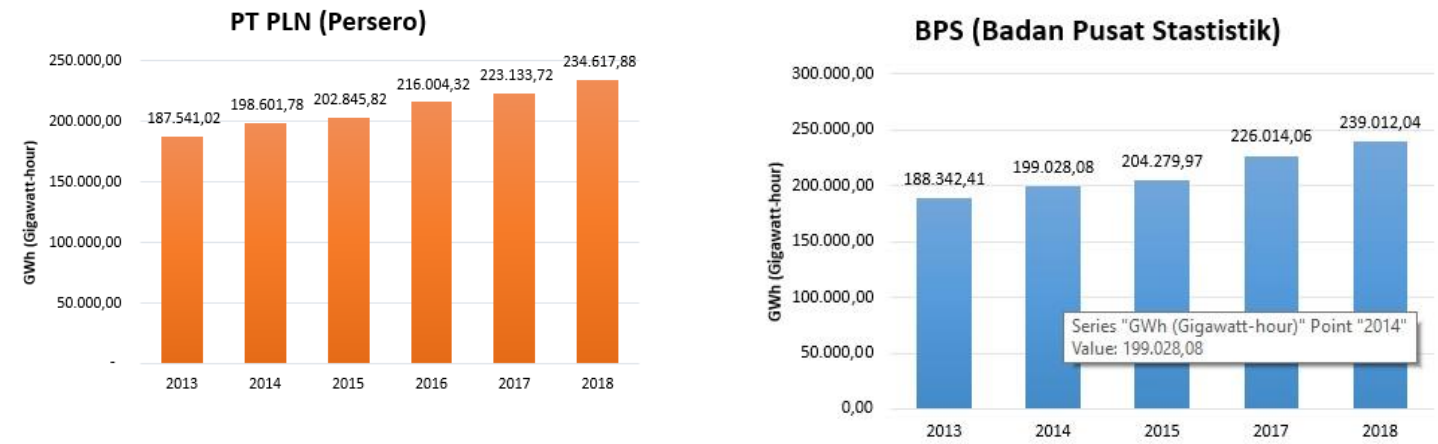

Gambar 1. Grafik Peningkatan Penggunaan Daya Listrik Indonesia

Menurut data penggunaan listrik negara tahun 2013 - 2018 dari data PT PLN (Persero) dan data dari BPS (Badan Pusat Stastistik) menunjukkan bahwa kedua data memiliki pola yang sama terutama pola peningkatan tiap tahunnya [9][10][11]. Hal ini berartipenggunaan daya listrik Indonesia yang meliputi 6 sektor yaitu rumah tangga, industri, bisnis, sosial, gedung kantor pemerintahan, dan penerangan jalan umum mengalami peningkatan penggunaan jumlah daya listrik setiap tahunnya [12][13].

Salah satu cara yang bisa dilakukan untuk mengurangi dampak lonjakan konsumsi daya listrik adalah dengan cara prediksi efektifitas penggunaan daya listrik menggunakan algoritma greedy. Upaya ini diharapkan dapat mengoptimalkan penggunaan daya listrik bulanan dalam kehidupan masyarakat sehari-harinya [14]. Dampaknya akan meningkatkan efektifitas terhadap pola penggunaan perangkat elektronik. Sehingga, walaupun tercipta pola peningkatan pada jumlah daya listrik. Namun pemanfaatan daya listrik yang dikonsumsi tiap bulannya tetap stabil atau diharapkan bisa menurun [15].

Juwita (2017) menyatakan bahwa algoritma Greedy merupakan teknik pemecahan beragam masalah untuk mencapai solusi paling optimal (maksimum atau minimum) yang pada tiap langkahnya terdapat banyak pilihan yang harus dibuat keputusan guna mencapai hasil akhir paling optimal. Pada penelitiannya, metode greedy digunakan untuk mengatasi permasalan Knapsack, yaitu permasalahan optimasi yang objeknya dibatasi oleh ruang dan wadah. Dengan algoritma Greedy diharapkan dapat mengoptimalkan penggunaan energi listrik. Walaupun pada prakteknya penyelesaian masalah dengan algoritma Greedy tidak selalu memberi hasil yang optimal ataupun efektif [8].

Berdasarkan latar belakang diatas, rumusan masalah pada penelitian ini yaitu bagaimana rancangan alat monitoring penggunaan daya listrik menggunakan algoritma greedy untuk mengatur pola penggunaan perangkat elekronik dan bagaimana mengintegrasikan serta mengimplementasikan alat monitoring penggunaan daya listrik dengan aplikasi android.

\section{METODE PENELITIAN}

Listrik saat ini menjadi kebutuhan pokok bagi masyarakat. Listrik merupakan sumber energi sangat dibutuhkan untuk memenuhi kebutuhan rumah tangga, industri, maupun pemerintahan. Dengan banyaknya permintaan maka terjadilah lonjakan penggunaan energi listrik. Disamping hal itu, saat ini untuk mengetahui penggunaan energi listrik hanya dipantau menggunakan kWh (Kilowatt jam) meter, sehingga untuk mengetahui banyaknya penggunaan listrik pada suatu ruangan belum memungkinkan.

Dari kasus tersebut peneliti memiliki suatu gagasan untuk membuat sistem yang mana dapat membantu mengatur pola penggunaan listrik suatu ruangan dengan algoritma greedy agar mencapai target efektifitas yang diharapkan. sistem ini memiliki 3 komponen inti dalam menjalankan prosesnya. Pertama, sistem memiliki sebuah alat untuk merekam konsumsi daya dari perangkat elektronik. Saat proses merekam alat membaca data arus, tegangan, dan sinyal koneksi Wi-Fi. Data dari sensor arus dan tegangan diproses menjadi data daya listrik. Lalu pada komponen kedua, data dari alat dilanjutkan ke server untuk diproses merubah data daya (watt) menjadi data konsumsi daya dalam bentuk kWh. Data yang sudah diproses akan dicatat dan dimasukan ke dalam tempat penyimpanan data (Database). Server juga akan mengirimkan pesan notifikasi ke ponsel untuk memberitahu informasi penggunaan daya tiap 3 jam sekali. Komponen ke 3 adalah aktifitas di ponsel yang ditangani oleh sebuah aplikasi. Aplikasi ini akan berperan dalam monitoring (pemantauan) dan sekaligus 
JSAI : Journal Scientific and Applied Informatics

Vol. 3, No. 3, November 2020, hal. 163-174

E-ISSN: 2614-3054; P-ISSN: 2614-3062, accredited by Kemenristekdikti, Sinta 5

DOI: 10.36085

memproses data penggunaan listrik dengan algoritma greedy untuk mengatur pola penggunaan listrik supaya memenuhi indeks intensitas konsumsi energi yang diharapkan.

\subsection{Perancangan Sistem}

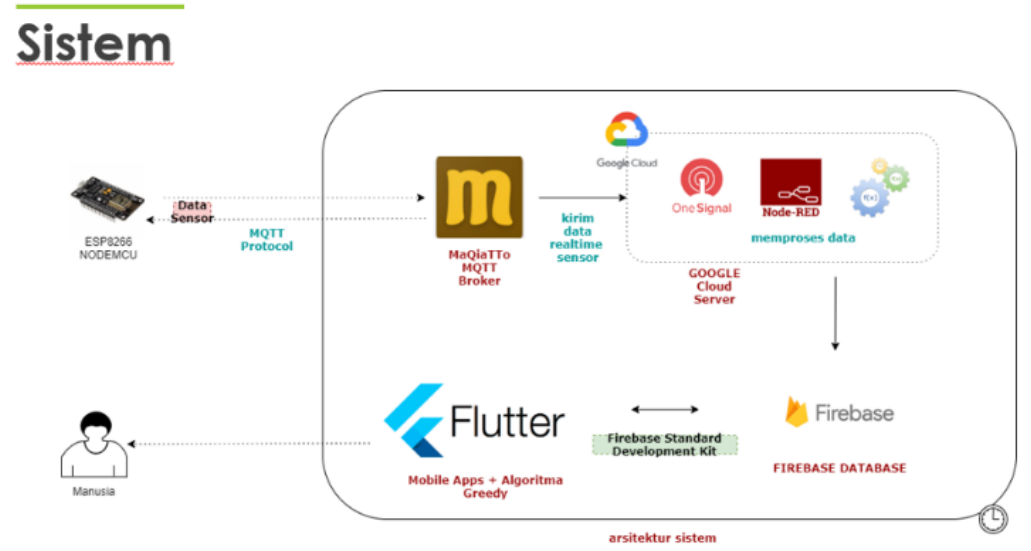

Gambar 2. Alur Perancangan Sistem

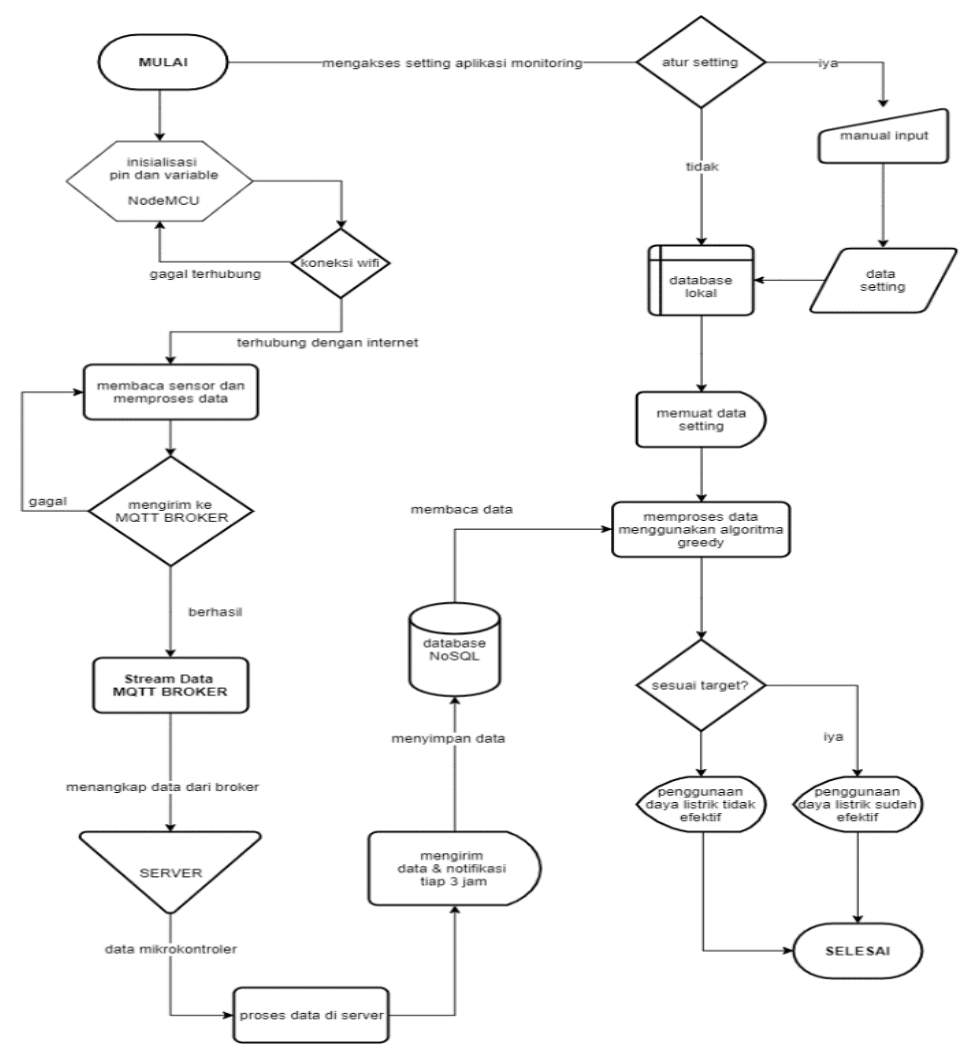

Gambar 3. Flowchart Alur Sistem

Secara garis besar urutan alur sistem dari monitoring dan prediksi efektifitas penggunaan daya listrik menggunakan algortima greedy sebagai berikut :

a. Awal mula mikrokontroler akan meminta akses internet ke jaringan Wi-Fi (Wireless Fidelity) jika berhasil akan melanjutkan proses alur, kalau gagal akan mencoba menghubungkan koneksi kembali. Arus listrik melewati sensor YHDC STC-013 sebagai pembaca arus (AC) dengan satuan Ampere.

b. Tegangan listrik melewati sensor ZMPT101B sebagai pembaca tegangan bolak-balik (AC) dengan satuan Volt. Sebelum data dikirim dari mikrokontroler ke MQTT Broker. 
c. Data diproses dahulu menjadi format daya (watt). Dari perhitungan rumus $\mathrm{P}=\mathrm{V} \mathrm{x} \mathrm{I}$. $\mathrm{P}=$ daya listrik, $\mathrm{V}=$ tegangan, dan $\mathrm{I}=$ arus. Setelah diproses, data di kirim ke MQTT Broker dengan catatan MQTT Broker tidak melakukan proses penyimpanan data dari mikrokontroler dan hanya menampilkan aliran saja (streaming data).

d. Server membaca aliran data secara berulang (subscribe) di MQTT Broker. Di server data dari MQTT Broker diproses menjadi format $\mathrm{kWh}$ (kilowatt jam) dari perhitungan ( $\mathrm{kWh}=$ Total rekaman daya dalam waktu 3 jam / 10800) . 1 jam sama dengan 3600 detik. Jika 3 jam $=3600$ x $3=10800$. Salah satu alasan menggunakan waktu 3 jam adalah untuk mengurangi beban terhadap server dan database. Kalkulasi diatas berakar pada rumus dasar Energi Listrik.

e. Hasil dari proses data akan di simpan di database NoSQL tiap 3 jam menggunakan cron job untuk penjadwalan otomatis. Selain itu pengguna akan mendapatkan notifikasi penggunaan energi listrik selama 3 jam di telepon selular.

f. Aplikasi monitoring di telepon seluler bersistem operasi android akan menampilkan data langsung penggunaan listrik (volt, ampere, dan watt) dan kalkulasi IKE (intensitas konsumsi energi) bulanan apakah sudah sesuai target yang ditentukan atau belum. Kalkulasi IKE merupakan salah satu proses penerapan algoritma greedy.

\subsection{Perancangan Database}

Sistem memerlukan basis data (database) untuk menyimpan nilai dari pembacaan sensor, nantinya data tersebut dapat digunakan untuk kalkulasi atau prediksi efektifitas penggunaan daya listrik. dari uraian diatas maka peneliti membutuhkan database untuk menyimpan data sampai data digunakan, peneliti memilih layanan Firebase Database (NoSQL) sebagai tempat penyimpanan data. Jika istilah tabel di SQL, maka di database NoSQL menggunakan istilah dokumen. Namun baik tabel dan dokumen memiliki karakter dan cara kerja yang berbeda. Adapun format data dokumen kwh sebagai berikut :

Tabel 1. Stuktur Dokumen Penggunaan

\begin{tabular}{cc}
\hline Properti & Tipe Data \\
\hline current1 & double \\
power1 & double \\
current2 & double \\
power2 & double \\
total_power & double \\
total_current & double \\
kwh & datetime \\
Datetime & epoch \\
\hline
\end{tabular}

Tabel diatas merupakan format penyimpanan data dokumen hasil proses dari server dalam database NoSQL. Format data dalam dokumen NoSQL menggunakan format data JSON (Javascript Object Notation). JSON merupakan suatu format ringkas pertukaran data komputer. Formatnya berbasis teks dan terbacamanusia serta digunakan untuk merepresentasikan struktur data sederhana. JSON sendiri memiliki 2 stuktur didalam datanya yaitu properti dan nilai. Data diatas selanjutnya akan dikonsumsi oleh aplikasi monitoring pada telepon selular bersistem operasi android.

\subsection{Perancangan Alat}

Langkah berikutnya dilakukan perancangan alat yang memuat kompokonen penyusun dari skematik elektronik seperti ditunjukkan pada gambar berikut: 


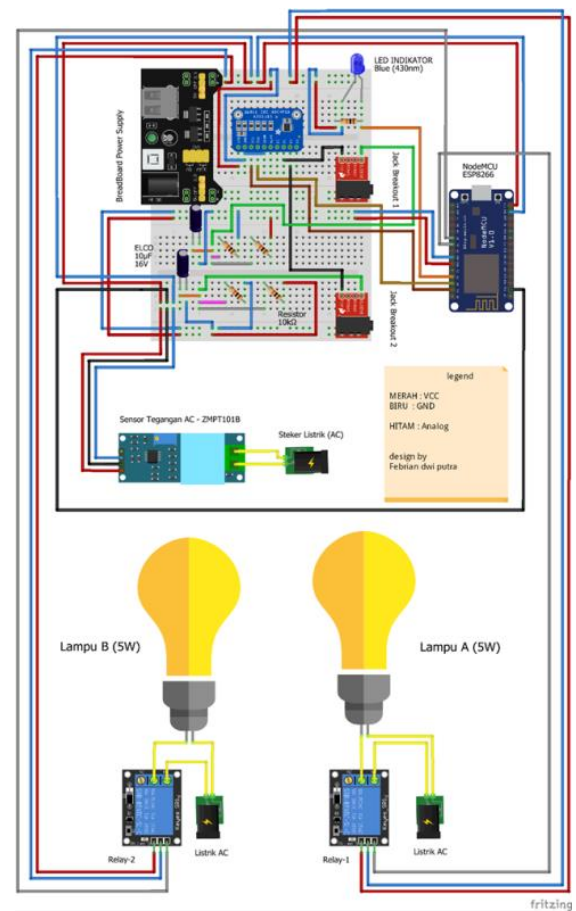

Gambar 4. Skema Elektronik Alat

Pada perancangan komponen akan diuraikan penjelasan gambar dari skematik elektronik dari alat monitoring dari awal sampai akhir perakitan :

a. Kabel merah merupakan VCC menunjukkan pin yang harus disambung ke tegangan positif ( $5 \mathrm{~V}$ atau $3.3 \mathrm{~V})$.

b. Kabel biru merupakan Ground menunjukkan pin harus disambungkan ke tegangan negatif $(0 \mathrm{~V})$.

c. Kabel hitam merupakan penghubung ke pin analog ADC (Analog To Digital Converter).

d. Kabel abu-abu menghubungkan Resistor B (bertegangan positif) dengan beberapa komponen seperti ELCO, pin Sleeve di TRSS Jack Breakout, dan Resistor A yang bermuatan tegangan negatif.

e. Kabel pink menghubungkan Resistor A (bertegangan negatif) dengan beberapa komponen seperti ELCO, pin Sleeve di TRSS Jack Breakout, dan Resistor B yang bermuatan tegangan positif.

f. Kabel biru muda menghubungkan ELCO dengan beberapa komponen seperti Resistor B, pin Sleeve di TRSS Jack Breakout, dan Resistor A.

g. Kabel hijau menghubungkan pin Sleeve pada komponen TRSS Jack Breakout dengan ELCO, Resistor A dan Resistor B.

h. Kabel coklat tua menghubungkan data digital pada pin D1 di mikrokontroler dengan pin SCL di ADS1115.

i. Kabel kuning menghubungkan antara sensor tegangan (ZMPT101B) dengan Steker Listrik AC.

j. Kabel coklat muda menghubungkan data digital pada pin D2 di mikrokontroler dengan pin SDA di ADS1115.

k. Kabel jingga menghubungkan data digital pada pin D3 di mikrokontroler dengan LED.

1. Relay-1 dan Relay-2 dihubungkan dengan pin digital D6 \& D7 pada NodeMcu agar dapat mengkontrol lampu melalui mikrokontroler. Relay membutuhkan tegangan sebesar $5 \mathrm{~V}$ maka akan dihubungkan ke tegangan positif (+) pada BreadBoard Power Supply yang telah dikonfigurasi keluaran tegangan menjadi 5V dan juga tegangan negatif (-) dihubungkan ke GND (Ground) pada relay.

m. Kedua Lubang pada Jack Breakout $1 \& 2$ dihubungkan dengan colokan jack yang ada pada sensor arus YHDC STC-030 30A. agar alat dapat mengamati arus pada perangkat uji coba (Lampu).

n. Pemasangan relay ke listrik AC dan lampu menggunakan konfigurasi NO (Normally Open) yaitu dimana kondisi awal relay pada posisi terbuka, tetapi saat tealiri arus maka akan ke posisi tertutup. Pin IN pada kedua modul relay dihubungkan dengan pin digital D6 dan D7 pada mikrokontroler Nodemcu.

\subsection{Perancangan Server}

Setelah merancang alat monitoring maka selanjutnya merancang server pada sistem. Server digunakan sebagai pihak penengah antara komponen sistem alat dan aplikasi android. Sistem yang dirancang berisi proses 
penyimpanan data ke database NoSql. Alur dari sistem dimulai server membaca data sensor yang dikirimkan oleh alat melalui protokol MQTT di MQTT Broker dengan cara mengakses Topic yang menampung data sensor. Setelah data berhasil dibaca maka akan dilakukan pemprosesan data mentah menjadi data berformat $\mathrm{kWh}$ dengan cara mengirim data ke Realtime database. Selanjutnya data yang ada di Realtime database akan dijumlahkan dengan data yang baru diproses. Proses ini akan terus berulang sampai 3 jam. Setelah 3 jam sistem penjadwalan Cronjobs akan mengeksekusi perintah pembacaan dari database firebase Realtime. Data dari firebase Realtime akan dikirim ke database penyimpanan yaitu database firebase cloud firestore. Tak hanya itu cronjobs akan mengeksekusi pengiriman pesan konsumsi daya selama $3 \mathrm{jam}$. Namun jika pembacaan dokumen di database firebase Realtime gagal atau dokumen tidak ada maka akan dilakukan reset skema dokumen koleksi penghitungan kwh.

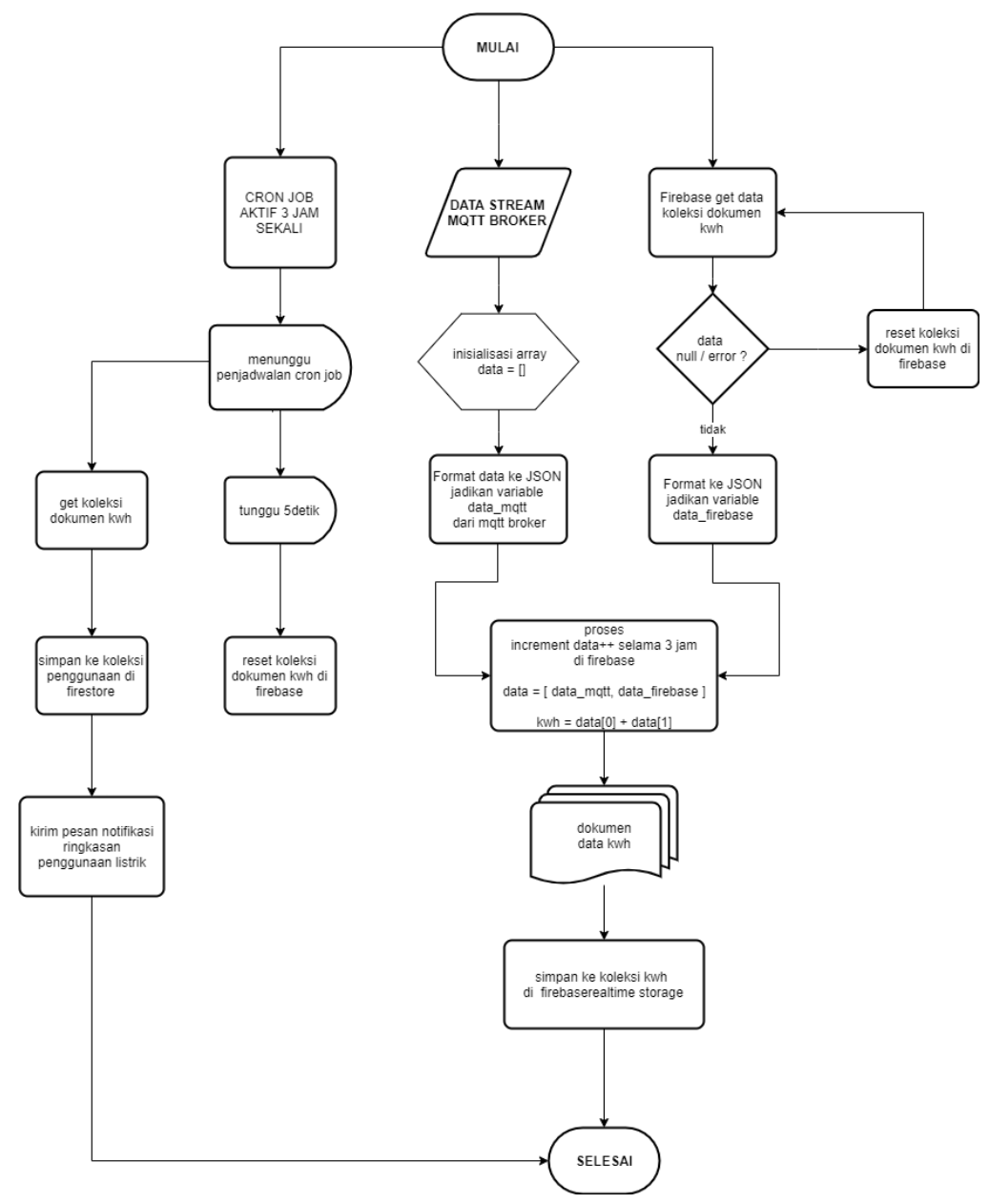

Gambar 5. Bagan Alur Server

\subsection{Perancangan Aplikasi Android}

Setelah merancang alat monitoring dan program server. Langkah terakhir adalah membuat rancangan sistem aplikasi. Pada sistem aplikasi dipilih sesuai kebutuhan yaitu merancang aplikasi berbasis android. Untuk teknologi membangun aplikasi android menggunakan SDK (Standard Development Kit) flutter berbahasa pemprograman dart. Flutter merupakan pendatang baru didunia pengembangan aplikasi ponsel. Dengan flutter memungkinkan membuat aplikasi diberbagai platform.

Untuk saat ini flutter mendukung pengembangan aplikasi android, ios dan web dalam satu kode yang sama. Peneliti hanya fokus pada pengembangan aplikasi android. Fungsi dari yang dirancang untuk menampilkan informasi agar pengguna tahu penggunaan daya listrik yang telah dikonsumsi. Setelah tahu dapat dilakukan tindakan pencegahan untuk meningkatkan efektifitas penggunaan daya listrik. Alur dari sistem aplikasi android yaitu berawal dari aplikasi membaca data total kwh dari database firebase cloud firestore. Lalu diproses lain aplikasi meminta untuk memasukan data setelan seperti luas area dan target batasan IKE (Intensitas Konsumsi Energi). Data setelan akan dimuat dan diproses bersama data yang diambil dari database. Setelah diproses akan menghasilkan nilai standar IKE. Lalu nilai standar hasil proses dicocokan dengan target batasan IKE yang di terapkan di setelan. Jika tidak sesuai atau melebihi maka penggunaan masih belum efektif dan efisien. 

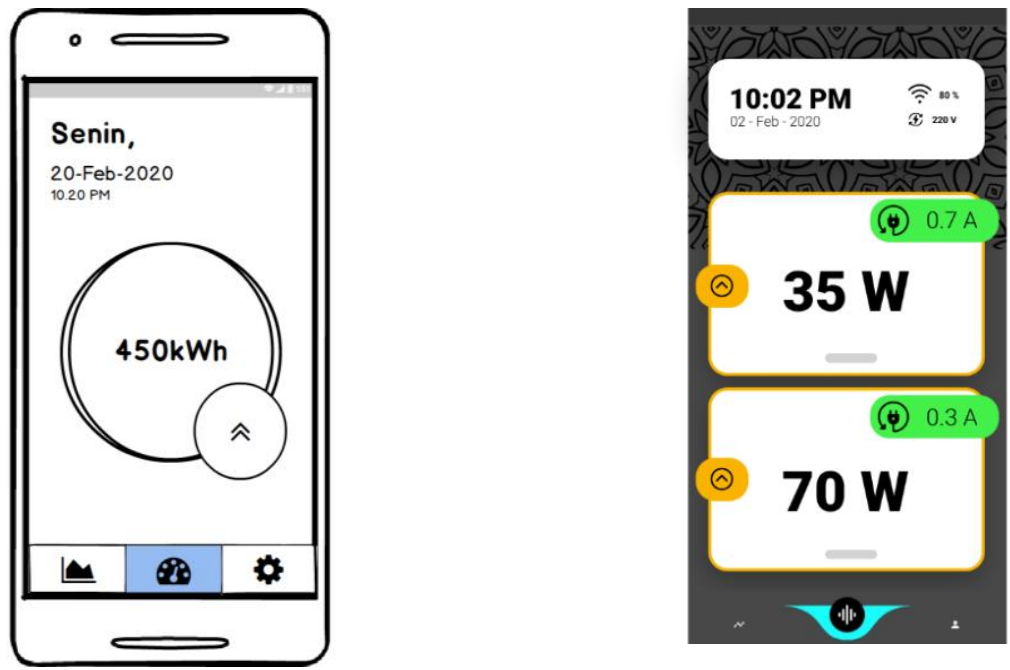

Gambar 6. Rencana Rancangan Kerangka (kiri) dan Desain Antarmuka (kanan) Pada Aplikasi

\section{HASIL DAN ANALISIS}

Dalam pengujian sistem terdapat hal-hal yang harus di uji terlebih dahulu untuk menentukan bahwa sistem dapat teruji dan siap berjalan sesuai dengan rancangan. Oleh karena dalam sistem akan dilakukan uji coba terhadap 3 hal yaitu alat, server, dan aplikasi agar mengetahui sistem dapat berjalan sesuai rancangan. Pengujian pada penelitian ini berfokus pada penggunaan 2 lampu dengan daya 5 watt dengan merk yang sama dipasang di sebuah ruangan. Tujuan akhir dari penelitian adalah mengetahui pola penggunaan yang memiliki efektifitas paling tinggi dengan bantuan algoritma greedy.

\subsection{Uji Coba Alat}

Sebagai upaya untuk menguji sistem maka dilakukan pengujian alat dari perbandingan pengukuran arus Clampmeter dengan alat monitoring seperti terlihat pada gambar 7.
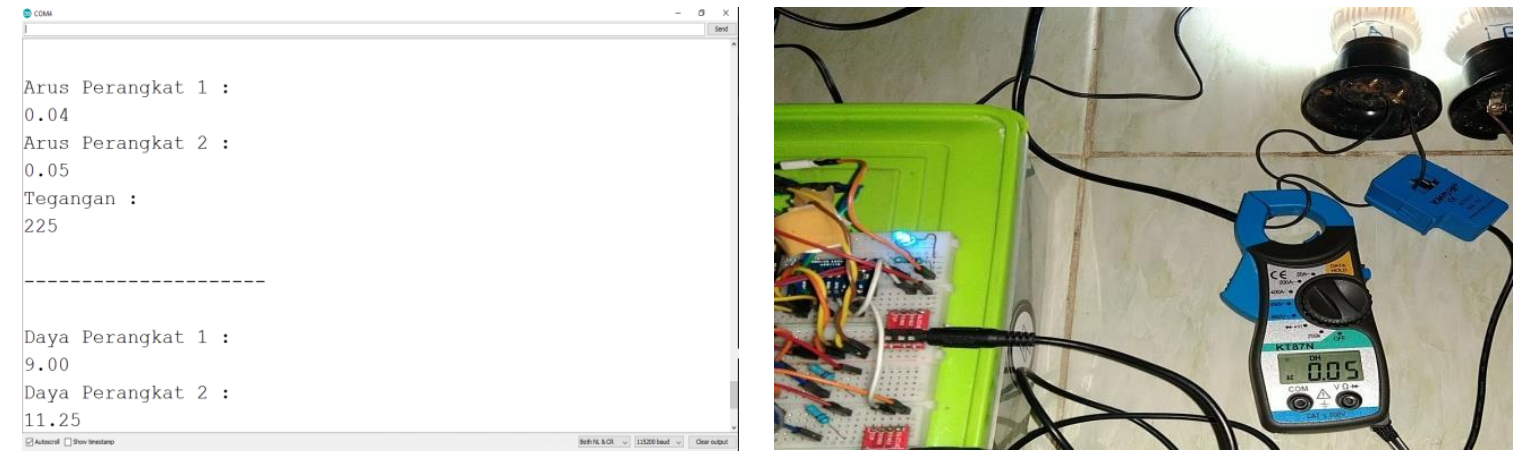

Gambar 7. Perbandingan Pengukuran Arus Clampmeter dengan alat monitoring pada lampu A 


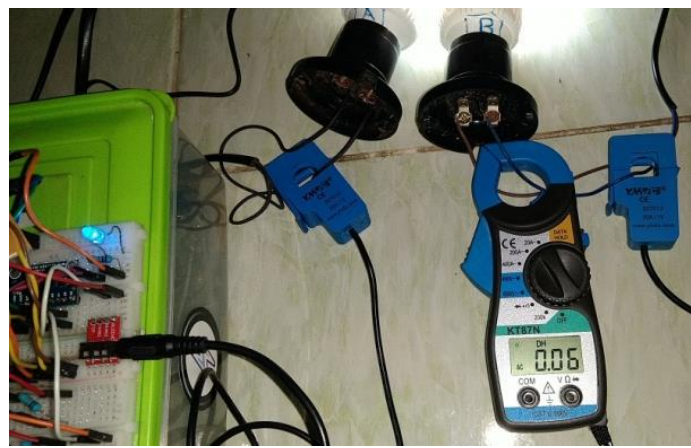

Gambar 8. Perbandingan Pengukuran Arus Clampmeter dengan alat monitoring pada lampu B

\section{Rumus Perhitungan Akurasi:}

$$
\text { Akurasi }=100 \%-\left(\left(\frac{\text { Nilai Alat }- \text { Nilai Clamp Meter }}{\text { Nilai Clamp Meter }}\right) \times 100 \%\right)
$$

Rumus Perhitungan Daya Listrik (w):

$$
P=I x V
$$

Keterangan:Listrik

I : Arus Listrik

V: Tegangan

$P$ : Daya listrik

Tabel 2. Hasil Pengujian Akurasi antara alat Zpower dan Clamp meter

\begin{tabular}{lllllllllll}
\hline & & \multicolumn{2}{c}{ Alat Zpower } & \multicolumn{4}{c}{ Clamp Meter } & \multicolumn{3}{c}{ Akurasi (\%) } \\
\cline { 2 - 10 } No. & Perangkat & I & V & P & I & V & P & I & V & P \\
\hline 1. & $\begin{array}{l}\text { Lampu A } \\
\text { Perangkat 1 } \\
(\text { PTB-2205) }\end{array}$ & 0,04 & 225 & 9,0 & 0,06 & 222 & 11,1 & 99,7 & 99 & 99,8 \\
\hline 2. & $\begin{array}{l}\text { Lampu B } \\
\text { Perangkat 2 } \\
(\text { PTB-2205) }\end{array}$ & 0,06 & 220 & 13,20 & 0,06 & 222 & 13,32 & 100 & 99 & 99,9 \\
\hline
\end{tabular}

Hasil pengujian alat yang telah dirancang dalam bab sebelumnya. Guna alat tersebut untuk membantu memonitoring atau melakukan pemantauan dalam penggunaan daya listrik. Hasil dari kalkulasi akurasi dapat membandingkan kondisi perbedaan keluaran nilai antara alat yang dirancang dengan clamp meter digital. Tabel diatas memperlihatkan perbedaan keakuratan antara dua komponen. Sering kali hal ini dikarenakan adanya noise pada proses pembacaan ADC (Analog To Digital) di modul ADS1115 atau di pin analog bawaan NodeMcu. Noise yang terjadi pada proses sampling sinyal analog sensor arus listrik ke dalam bentuk nilai digital atau dari penggunaan komponen atau penyusunan rangkaian elektronik dari alat yang telah dibangun. Untuk penggunaan atau kalkulasi besaran burden resistor untuk sensor arus tidak dilakukan dan digunakan. Alasannya dipenelitian ini menggunakan tipe sensor arus YHDC seri STC-013-30 dan nodemcu dengan suplai tegangan 3.3V. STC-013-30 tidak seperti tipe seri STC-013-000 yang mengharuskan kalkulasi mencari besaran burden resistor dan memakainya sebagai external burden resistor.

Dikarenakan pada seri STC-013-000 tidak memiliki internal sampling burden resistor pada unitnya ditambah jika penggunaan dengan suplai $5 \mathrm{~V}$ dari mikrokontroler mengharuskan mencari besaran burden resistor atau besaran beban resistor untuk akurasi pembacaan dan perlindungan unit. Pada seri STC 013-30 memiliki internal sampling burden resistor bawaan sebesar $62 \mathrm{ohm}$. Namun tidak menutup kemungkinan besaran nilai burden berubah pada tiap unit yang dijual. Sebab, pabrikan cenderung menyesuaikan nilai dari kumpulan unit ke kumpulan unit untuk mendapatkan kinerja yang ditentukan.

\subsection{Pengujian Server dan Aplikasi}

Pada pengujian program server dan aplikasi dilakukan menggunakan metode blackbox. Metode blackbox merupakan pengujian yang dilakukan hanya mengamati hasil eksekusi melalui data input dan memeriksa 
JSAI : Journal Scientific and Applied Informatics

Vol. 3, No. 3, November 2020, hal. 163-174

E-ISSN: 2614-3054; P-ISSN: 2614-3062, accredited by Kemenristekdikti, Sinta 5

DOI: 10.36085

fungsional dari perangkat lunak. Bisa digambarkan sederhana metode black box seperti melihat kotak hitam yang kita tak tahu isi detail apa dalam kotak tersebut. Hanya mengetahui inputan dan outputan saja.

\subsection{Hasil Penelitian}

Bagian ini membahas hasil akhir perancangan dari aplikasi dan alat monitoring. Alat monitoring yang berhasil dirancang terlihat pada gambar 9 .

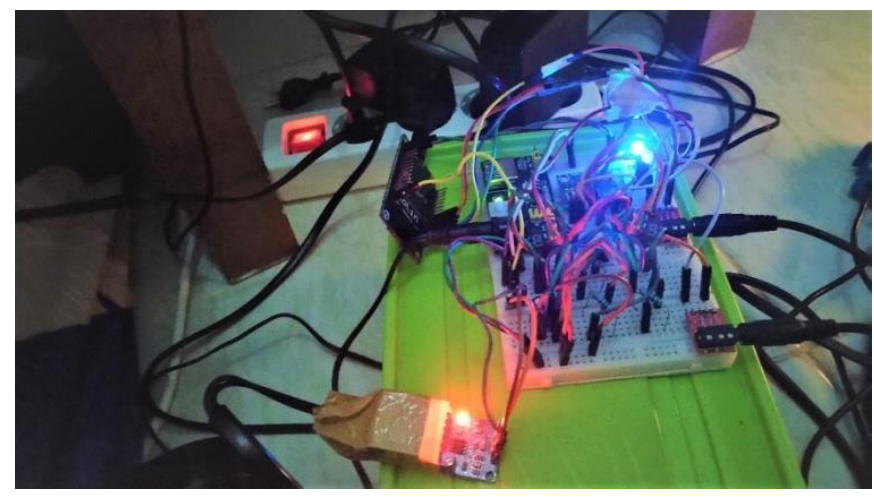

Gambar 9. Hasil Alat Monitoring

Selanjutnya fitur dalam aplikasi androidnya terlihat pada gambar berikut:
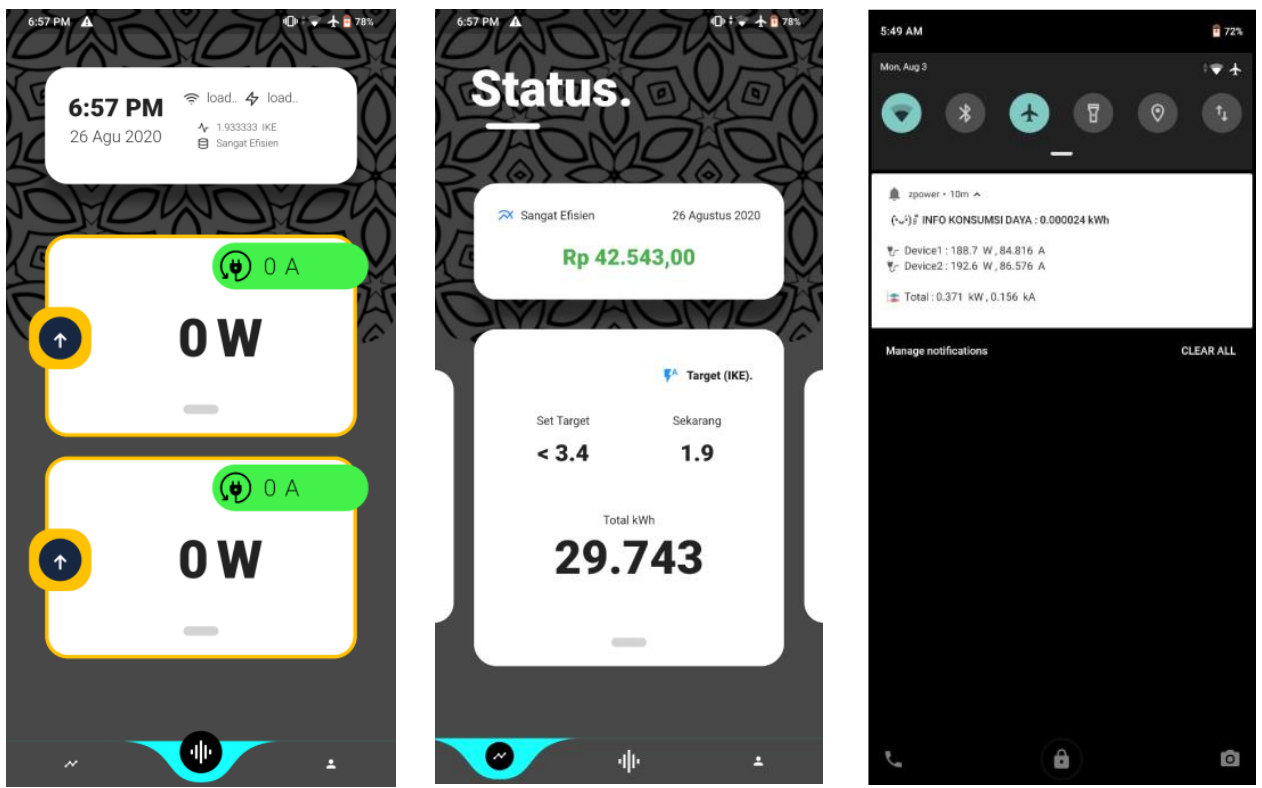

Gambar 10. Hasil Aplikasi Android (Ponsel)

\subsection{Simulasi Sistem}

Pada bab ini menguraikan hasil uji coba simulasi sederhana yaitu membandingkan pola penggunaan daya listrik normal dan menggunakan algoritma greedy dengan studi kasus sebuah bangunan memiliki 2 ruangan yaitu ruang tengah (R1) dan kamar tidur (R2). R1 memiliki panjang dan lebar 8m x 5m sedangkan kamar tidur $3 \mathrm{~m} \times 2 \mathrm{~m}$. kedua ruangan (R1 \& R2) menggunakan lampu dengan besaran daya $5 \mathrm{~W}$ dan merk yang sama. Tujuan dari penelitian, walaupun penggunaan listrik pada lampu saat pagi atau malam terus menyala tapi penggunaan daya listrik diharapkan tetap efektif (pemanfaatan tetap sesuai keinginan namun besaran penggunaan tidak mengalami peningkatan atau stabil). Dengan catatan ada kondisi khusus pada studi kasus simulasi yaitu jika kondisi lampu A nyala dan lampu B mati maka lampu A di ruang tengah (R1) dapat dimanfaatkan untuk menerangi ruangan kamar tidur (R2) namun tidak bisa sebaliknya (*pintu ruangan kamar tidur (R2) terbuka). Simulasi dilakukan dalam waktu 30 hari pada kedua pola. 


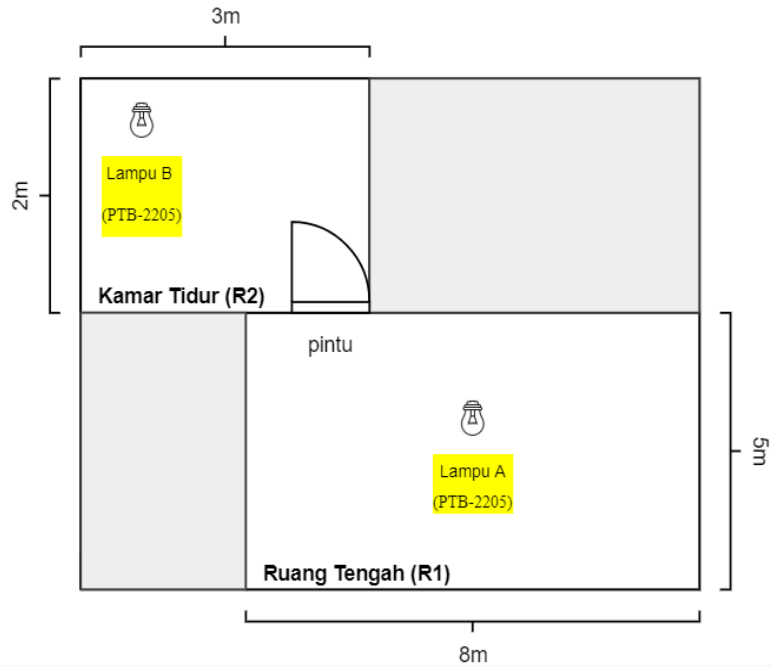

Gambar 11.Denah Ruangan yang menunjukkan posisi lampu A dan lampu B

Sebelum memulai simulasi dibutuhkan beberapa informasi terkait data pendukung yang ada pada studi kasus. Data tersebut sebagai bahan kalkulasi penentu efektifitas berdasarkan Nilai Standar IKE (Intensitas Konsumsi Energi) Peraturan Menteri ESDM Nomor 13 Tahun 2012. Infomasi yang diperluhkan adalah total luas area $\left(\mathrm{m}^{2}\right)$ yang dilayani oleh energi listrik (lampu) dan batasan IKE yang ditentukan. Data tersebut nantinya akan dimasukan ke dalam sistem aplikasi ponsel (android) yang telah dirancang sebelumnya.

Tabel 3. Data Rencana Penerapan Simulasi

\begin{tabular}{llllll}
\hline \multirow{2}{*}{ No. } & \multirow{2}{*}{ Pola Penggunaan } & Kondisi & \multirow{2}{*}{ Luas Area } & \multirow{2}{*}{ Batas IKE } \\
\cline { 3 - 5 } & & Pagi & Malam & & \\
\hline 1. & Normal & Nyala & Nyala & $77 \mathrm{~m}^{2}$ & $<3,4$ \\
\hline 2. & Greedy & Kondisional & Kondisional & $77 \mathrm{~m}^{2}$ & $<3,4$ \\
\hline
\end{tabular}

Rumus menghitung total luas area:

$$
T L A\left(m^{2}\right)=(p R 1+p R 2) x(I R 1+I R 2)
$$

\section{Keterangan:}

TLA : Total Luas Area

pR1 : Panjang Ruangan R1 (ruang tengah)

IR1 : Lebar Ruangan R1 (ruang tengah)

pR2 : Panjang Ruangan R2 (kamar tidur)

IR2 : Lebar Ruangan R2 (kamar tidur)

Setelah dilakukan Uji Simulasi pada sistem menggunakan 2 pola penggunaan energi listrik yang berbeda yaitu normal dan greedy didapatkan data yang menunjukan perbedaan antara penggunaan energi listrik normal dan penerapan algoritma greedy. Data grafik perbandingan dan hasil simulasi bisa dilihat pada tabel 4 dan Gambar 12 dibawah ini:

Tabel 4. Hasil dari Penerapan Simulasi

\begin{tabular}{llllll}
\hline \multirow{2}{*}{ No. } & Pola Pengguna & Hasil & \multicolumn{3}{l}{ Target } \\
\cline { 3 - 6 } & & kWh & IKE & IKE & Batasan \\
\hline 1. & Normal & 371,68 & 4,83 & $<3,4$ & Tidak \\
\hline 2. & Greedy & 258 & 3,35 & $<3,4$ & Iya \\
\hline
\end{tabular}




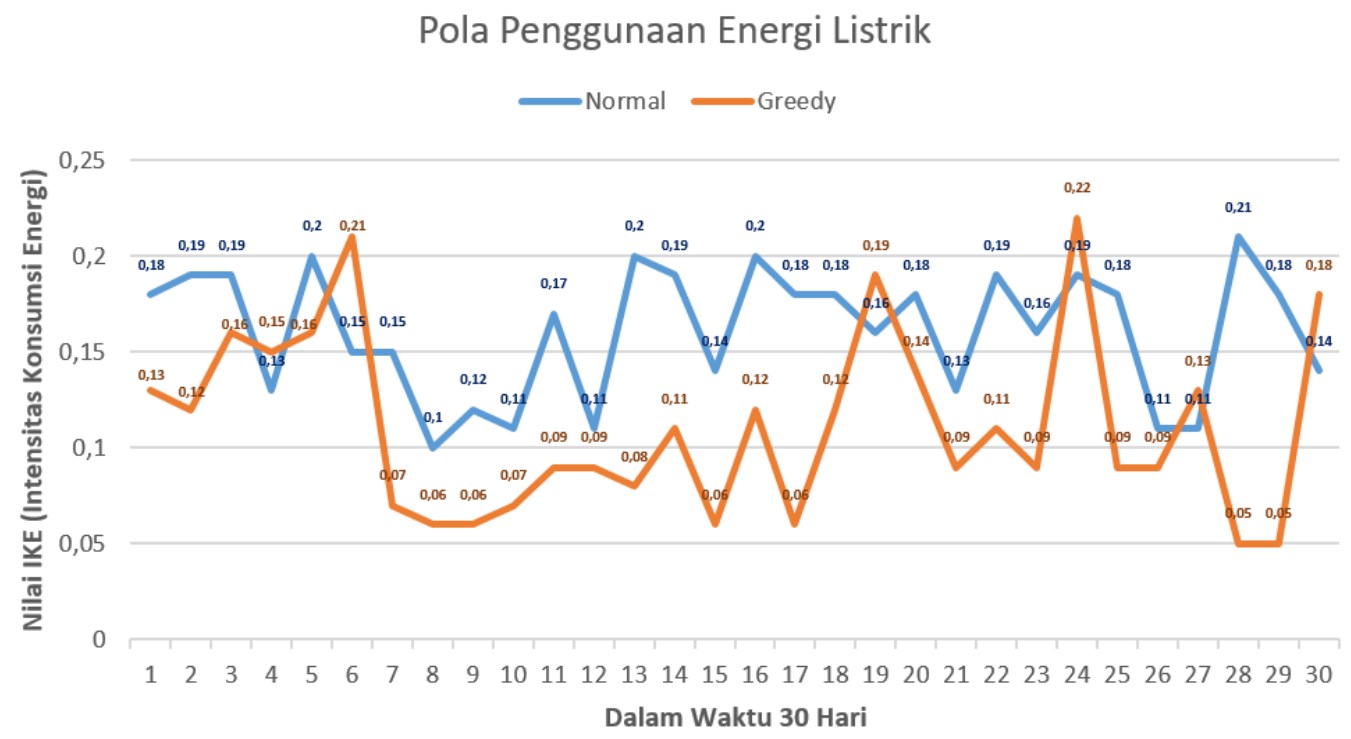

Gambar 12. Grafik Perbandingan

Dari kedua data diatas dapat diuraikan walaupun kondisi penggunaan lampu pada ruangan dengan pola normal dan greedy sama yaitu kondisi dimana kedua pola sama-sama menyalakan lampu pada waktu pagi dan malam. Namun dari kedua pola terjadi perbedaan pada total IKE (Intensitas Konsumsi Energi) dalam waktu 30 hari. Total IKE pada pola penggunaan normal mendapatkan nilai sebesar 4,8 dan batasan target yang ditetapkan $<3,4$. Bisa dikatakan hasil total IKE pada pola penggunaan normal melebihi batasan target. Sedangkan pola penggunaan dengan penerapan algoritma greedy mendapatkan total nilai sebesar 3,3 sedangkan batasan target IKE yang ditetapkan sama dengan pola penggunaan normal yaitu $<3,4$. Tidak seperti pola penggunaan normal, pada pola penggunaan greedy tidak melebihi batasan karena nilai total IKE dibawah batasan target IKE yang ditetapkan. Perichappan (2018), menyatakan bahwa algoritma greedy memberikan keakuratan prediksi yang diterapkan menggunakan pendekatan yang diusulkan terhadap jumlah sesi. Ini menunjukkan kecenderungan yang baik untuk diterapkan dalam prediksi yang memakan waktu.

Algoritme greedy dapat sangat efisien ketika menangani kumpulan data yang besar, dalam arti bahwa jika solusi optimal dari masalah secara global terdiri dari solusi optimal dari sub-masalah yang optimal secara lokal, maka pencarian greedy akan menemukan solusi global dalam waktu yang wajar (Algorithm, 2001). Operasional algoritma greedy nilai akhir yang dihasilkan oleh algoritme dan deviasi standar dalam nilai efisiensi yang dihitung untuk nilai awal yang sama adalah kriteria utama untuk evaluasi kinerja antar algoritme, mampu memberikan pencarian Greedy acak berkinerja terbaik (Biswas dan Chilukuri 2015).

\section{KESIMPULAN}

Berdasarkan hasil implementasi dan pengujian yang telah dilakukan sebelumnya, maka dapat disimpulkan bahwa:

a. Impelemenasi MQTT Broker dan protokol MQTT pada sistem yang dirancang dapat memudahkan pemantauan penggunaan daya listrik secara jarak jauh, hanya cukup menggunakan telepon genggam, mengaktifkan data internet dan alat terkoneksi dengan internet sudah dapat memantau kapanpun dan dimana saja.

b. Banyak faktor mempengaruhi tingkat keakuratan keluaran nilai daya listrik yang dihasilkan oleh alat monitoring, mulai dari segi pemilihan seri tipe sensor arus, banyaknya noise saat pengambilan data penggunaan daya listrik dan juga kestabilan sistem dibagian mikrokontroler, server ataupun pada aplikasi android.

c. Penerapan algoritma Greedy dalam menentukan batasan pada sistem berdasarkan standar nilai IKE (Intensitas Konsumsi Energi) memudahkan mengetahui status penggunaan konsumsi listrik.

\section{REFERENSI}

[1] Algorithm, G. (2001) Encyclopedia of Mathematics. Springer Science + Business Media B.V./Kluwer Academic Publishers, Berlin.

[2] Badan Pusat Stastistik. (2019), Stastistik Listrik 2013-2018, BPS, Indonesia. 
[3] Badan Pusat Stastistik. (2019). Stastistik Listrik 2013-2018. Indonesia : Badan Pusat Stastistik. (ISSN : $2354-6875)$.

[4] Bhaswara, Faizal Anugrah, Riyanarto Sarno, Dwi Sunaryono. 2017. Perbandingan Kemampuan Database NoSQLdan SQL dalam Kasus ERP Retail. Surabaya: Institut Teknologi Sepuluh Nopember (ITS). Jurnal Teknik ITS Vol. 6, No 2, September 2017.

[5] Biantoro, Agung Wahyu. 2017. Analisis Perbandingan Efisiensi Energi Pada Gedung P Kabupaten Tangerang Gedung Tower UMB Jakarta. Jakarta: Universitas Mercu Buana. Jurnal Teknik Mesin Vol. 6, No 3, Juni 2017.

[6] Biswas, Manek and Chilukuri K. Mohan (2015) Algorithms for the Implementation of a Dynamic Electrical Energy Pricing Policy. Procedia Computer Science 70: 668 - 675

[7] Guna, Putu Ivan Adi, I Made Arsa Suyadnya, I Gusti Agung Pt Raka Agung. 2018. Sistem Monitoring Penetasan Telur Penyu Menggunakan Mikrokontroler NodeMCU ESP8266 dan Protokol MQTT dengan Notifikasi. Bali : Universitas Udayana. Journal of Computer Science and Informatics Engineering (J-Cosine) Vol. 2, No 2, Desember 2018.

[8] Juwita, Putri Suryani, Erwin Susanto, dan Junartho Halomoan. 2017. Perancangan Dan Implementasi Manajemen Daya Listrik Menggunakan Algoritma Greedy Untuk Otomatisasi Rumah. Bandung : Universitas Telkom. TEKTRIKA - Jurnal Penelitian dan Pengembangan Telekomunikasi, Kendali, Komputer, Elektrik, dan Elektronika Vol. 2, No 2, Desember 2018.

[9] Kurniawan, Arief, Dahnial Syauqy, Barlian Henryranu Prasetio. 2017. Pengembangan Sistem Monitoring Listrik Pada Ruangan Menggunakan NodeMCU dan MQTT. Malang : Universitas Brawijaya. Jurnal Pengembangan Teknologi Informasi dan Ilmu Komputer Vol. 1, No. 6, Juni 2017.

[10] Oktaviana, Shinta, Abdurrahman Naufal. 2017. Algoritma Greedy untuk Optimalisasi Ruangan dalam Penyusunan Jadwal Perkuliahan. Jakarta : Politeknik Negeri Jakarta. Jurnal Multinetics Vol. 3 No. 1 Mei 2017.

[11] Parmana, Ignatius I Wayan Rexci Indra, Cok Gede Indra Partha, Ngakan Putu Satriya Utama. 2018. Rancang Bangun Sistem Monitoring Arus Beban pada Gardu Distribusi Menggunakan Short Message Service. Bali : Universitas Udayana. Majalah Ilmiah Teknologi Elektro. Vol. 17, No 1, April 2018.

[12] Perichappan, K.A.P. (2018) Greedy Algorithm Based Deep Learning Strategy for User Behavior Prediction and Decision Making Support. Journal of Computer and Communications, 6, 45-53. https://doi.org/10.4236/jcc.2018.66004

[13] PT PLN (persero). 2019. Stastistik PLN 2018. Indonesia : PT PLN (persero). (ISSN : 0852 - 8179).

[14] Rahmadan, Zakky, Sabriansyah Rizqika Akbar, Gembong Edhi Setyawan 2019. Implementasi Sistem Monitoring Daya Listrik Berbasis Web dan Protokol Komunikasi Websocket, Malang : Universitas Brawijaya. Jurnal Pengembangan Teknologi Informasi dan Ilmu Komputer Vol. 3, No. 1, Januari 2019.

[15] Rosli, Mohammad Nazri, Lukman Audah, Nor Shahida Mohd Shah. 2019. IoT Based Security System For A One Bed Hospital Room. Malaysia : Universiti Tun Hussein Onn Malaysia. 